\title{
Review
}

\section{Biohydrogen purification by membranes: An overview on the operational conditions affecting the performance of non-porous, polymeric and ionic liquid based gas separation membranes}

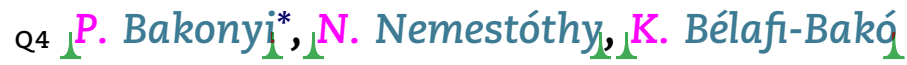 \\ Research Institute on Bioengineering, Membrane Technology and Energetics, University of Pannonia, Egyetem ut 10, \\ 8200 Veszprém, Hungary
}

\section{A R T I C L E I N F O}

Article history:

Received 25 March 2013

Received in revised form

18 May 2013

Accepted 28 May 2013

Available online $\mathrm{xxx}$

Keywords:

Biohydrogen

Membrane

Separation

Polymer

Ionic liquid

Integrated system

\begin{abstract}
A B S T R A C T
Many types of membranes are available to enrich hydrogen. Nevertheless, there are some with special potential for biohydrogen purification such as the non-porous, polymeric and ionic liquid based membranes. The attractiveness of these membranes comes from the fact that they can be employed nearly under the conditions where biohydrogen formation taking place. Therefore, they appear as promising candidates to be coupled with hydrogen producing bioreactors and hence giving the chance for in situ biohydrogen concentration. It is known that the feasibility and efficiency of membrane technology - beside material selection and module design - significantly depend on the separation circumstances. Thus, the operation of membranes is a key issue and the most important factors to be considered for gas purification are the composition of gas to be separated, the pressure and temperature applied. The scope of this study is to give a comprehensive overview on the recent applications of non-porous, polymeric and ionic liquid supported membranes for biohydrogen recovery, placing emphasis on the operational conditions affecting membrane's behavior and performance. Furthermore, a novel concept for integrated biohydrogen production and purification using gas separation membranes is demonstrated and discussed.
\end{abstract}

Copyright @ 2013, Hydrogen Energy Publications, LLC. Published by Elsevier Ltd. All rights reserved.

\section{Introduction}

Biologically generated hydrogen - referring to the term of biohydrogen - research represents one of the hottest topics in the field of bioenergetics due to the inherent benefits of hydrogen over the other energy carriers, particularly its unique, environmental-friendly features and high energy content on gravimetric bases [27].

Though biohydrogen shows a high potential for future's sustainable development, there are still pending issues concerning two major obstacles in the technology, namely the consecutive production and purification. These steps need to

\footnotetext{
* Corresponding author. Tel.: +36 88 624385; fax: +36 88624292
}

E-mail addresses: bakonyip@almos.uni-pannon.hu, bakonyipeter85@gmail.com (P. Bakonyi). 0360-3199/\$ - see front matter Copyright @ 2013, Hydrogen Energy Publications, LLC. Published by Elsevier Ltd. All rights reserved. http://dx.doi.org/10.1016/j.ijhydene.2013.05.158 
be further improved to make biohydrogen a more reliable option.

As a result of the recent decades, it can be concluded that among the several ways to produce biohydrogen, dark fermentation would appear to be the most feasible from various points of views such as high stability, simple control requirements, high volumetric productivity, etc. (Das and Veziroglu, 2008). This method enables one to achieve sufficient production rates by utilizing cheap and widely available organic wastes formed in large quantities globally. Although the dark fermentation is promising it usually suffers from low yields ( $\mathrm{mol} \mathrm{H}_{2} / \mathrm{mol}$ substrate) [34]. Thus, an essential task is to achieve improved substrate conversion efficiencies $[34,70]$. In recent years, it has turned out that the accumulation of hydrogen in the bioreactor is a significant reason for low biohydrogen yields because hydrogen evolution is highlysensitive to $\mathrm{H}_{2}$ concentration and is subject to product inhibition [71]. As hydrogen concentration increases in the bioreactor, $\mathrm{H}_{2}$ synthesis decreases and metabolic pathways of

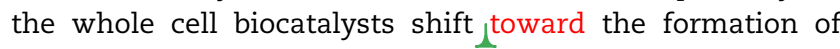
by-products such as lactate and other solvents (e.g. ethanol, acetone, butanol, etc.) $[71,55]$. Consequently, systems should properly be designed and operated to reduce $\mathrm{H}_{2}$ partial pressure - and thus the concentration of $\mathrm{H}_{2}$ dissolved in the fermentation broth - before it leads to the repression of its generation $[34,71,49,66]$.

For this purpose, various solutions such as nitrogen sparging, vigorous mixing have been proposed [71,53] but the development of novel methods is still needed e.g. by employing membrane separation. Membrane technology might aid to overcome the issue of low yields by allowing in situ and continuous removal of biohydrogen from the reactor. However, this approach is poorly investigated in spite of its particular attractiveness.

In theory, a wide range of membrane applications are available to complete the task of hydrogen separation and can be classified into categories such as organic (usually made of artificial polymers) and inorganic membranes. These groups can be subdivided into porous and non-porous membranes.

Metallic (e.g. palladium) and metallic alloy membranes are well-known members of the inorganic, non-porous class [103]. These are extremely selective to hydrogen but possess some drawbacks e.g. high cost, fragility and drastic operational circumstances (e.g. elevated temperature) that restrict its usefulness for biological systems.

The conventional porous, inorganic membranes separate gaseous compounds based on differences in molecular weight and diffusivity, representing an upper-limitation for the achievable process efficiency [69]. The porous, organic (polymeric) membranes derive their selectivity based on the similar principle. Nevertheless, such membranes are often used to fabricate membrane contactors (MC) and liquid membranes (LM).

In LMs, various liquids fill the pores of the organic (polymeric) membranes serving as support/carrier matrixes. Nowadays, ionic liquids are preferentially applied instead of the traditional organic solvents and thus supported ionic liquid membranes (SILMs) can be prepared. Through this approach, the originally porous, polymeric membranes are transformed into non-porous ones and perform separation based on a mechanism called solution-diffusion. A similar separation principle characterizes the conventional nonporous, organic (polymeric) membranes (NPPM), as well.

In MCs, a porous, organic (polymeric) membrane stands for a physical barrier between the gas to be separated and the absorption liquid. The separation is dependent on the affinity of gases to the absorption liquid employed and therefore MCs can be described as devices combining membrane and absorption technology.

As a matter of fact, among the various alternatives introduced so far, SILMs, NPPMs and MCs appear as the most potential candidates for biohydrogen enrichment since their operational requirements are close to those required for molecular hydrogen fermentation (nearly ambient temperature and pressure), where they might able to express sufficient separation performance.

Although membrane contactors are interesting and suitable options for the purification of gaseous mixtures with biological origin $[93,68,10,83]$, their application receives somewhat less attention in comparison with NPPMs and SILMs. Therefore, MCs are now beyond the scope of this paper and only non-porous, polymeric and supported ionic liquid membranes are focused.

It is widely known that the feasibility of a membrane based gas purification system is dependent on three main factors:

material selection for membrane fabrication

design and configuration of membrane modules operation conditions

Membrane gas separation - especially the progress in material engineering - has recently been addressed in depth from various aspects $[1,12,89,100]$. However, none of the research and review articles was specifically dedicated to membrane operation in the important field of biohydrogen recovery. Therefore, such a comprehensive overview was aimed to give in this paper. The effects of the most crucial operational factors influencing the performance of the nonporous, polymeric and ionic liquid based membranes for biohydrogen concentration were discussed. Moreover the concept of the Gas Separation Membrane Bioreactor - integrating hydrogen production and purification into a single system - as a possible innovative way in biohydrogen technology was presented. The particular benefits of this special set-up as well as some technical challenges were reviewed.

\section{The role of membranes in biohydrogen technology}

Membrane technology can play multiple roles in the development of biological systems [18] as well as in fermentative biohydrogen technology. For example, membrane bioreactors - employing submerged or externally (loop) connected porous, water filtration (micro-, ultra-, nanofiltration and reverse osmosis) membranes - are able to efficiently retain active biomass within the fermenter. Thus, compared to conventional free cell reactors, a significantly higher concentration of active, hydrogen producing biomass can be ensured leading to a definite increment in hydrogen turnover rate. 
Moreover, these systems - may be called as anaerobic membrane bioreactors (AnMBR) - can be characterized by enhanced stability and reliable operation as reported by various authors ([54,90], Lee and Chung, 2010).

Nonetheless, there is another type of membrane bioreactors, where gas separation membranes are built-in (Fig. 1) instead of their water filtration counterparts. Such an apparatus can be called as Gas Separation Membrane Bioreactor, abbreviated as GSMBR.

This application - as implied in Fig. 1 - possesses two benefits. Firstly, a portion of the feed introduced to the gas separation membrane (either permeate or retentate depending on the selectivity behavior of the membrane) which is lean in hydrogen and enriches gaseous fermentation products of no energetic value (e.g. $\mathrm{CO}_{2}$ and $\mathrm{N}_{2}$ ) can continuously be recirculated to the bioreactor. Thus, $\mathrm{bioH}_{2}$ could be diluted and due to its reduced partial pressure higher activity of the hydrogen producing microbial population is expected. On the top of an intensified biohydrogen turnout, hydrogen purification can simultaneously be performed, as well. Hence, concentrated bioH $\mathrm{H}_{2}$ could be obtained in a one-step process.

Despite the apparent advantages of these constructions, they received poor attention so far and only a couple of studies - dealing with the integration of biohydrogen generation and separation - can be referenced.

Teplyakov et al. coupled an active membrane system to the bioreactor to separate hydrogen. As reported, the experimental set-up could remove $\mathrm{CO}_{2}$ quite efficiently from the fermenter off-gas. The gas to be treated composed of approx. $80 \mathrm{vol} \% \mathrm{CO}_{2}$ and $20 \mathrm{vol} \% \mathrm{H}_{2}$ whilst the retentate stream contained 90 vol\% $\mathrm{H}_{2}$ and 10 vol\% $\mathrm{CO}_{2}$ [93].

In a research by Liang et al., $10 \%$ and $15 \%$ increase in the hydrogen production rate and yield was achieved, respectively, when silicon membrane was attached to the bioreactor [56].

Bélafi-Bakó et al. linked a two-stage membrane purification system directly to the hydrogen producing bioreactor. Their results demonstrated that it was possible to recover hydrogen from the multi-compound gaseous mixture formed during the bioconversion. In the permeate $\mathrm{H}_{2}$ could be enriched above $70 \mathrm{vol} \%$. It was suggested that a semi-continuous gas removal could enhance production process [11].

The separation of biohydrogen is considered as a key issue since only purified hydrogen can be used for power (electricity) generation in efficient fuel cell applications. To enrich biohydrogen, membrane technology is an appealing and prosperous alternative from various technological points of views, such as its environmentally benign nature, relative ease of scalability, portability, etc.

In fact, one more particular reason to combine hydrogen bioproduction and purification is that the membranes purposing to selectively concentrate biohydrogen have more often than not been characterized under ideal circumstances with pure gases and only less frequently with binary and ternary gaseous mixtures $\left(\mathrm{H}_{2} / \mathrm{CO}_{2}, \mathrm{H}_{2} / \mathrm{N}_{2}, \mathrm{H}_{2} / \mathrm{CO}_{2} / \mathrm{N}_{2}\right)$. For references, please see the subsequent chapters.

However, in real cases the gas obtained during the biohydrogen fermentation is a complex mixture of compounds $\left(\mathrm{H}_{2}, \mathrm{CO}_{2}, \mathrm{~N}_{2}\right)$ with several trace components (e.g. $\mathrm{H}_{2} \mathrm{~S}$ ) saturated with water. Consequently, extrapolating the performance of membranes from single or model gas measurements is not certainly reliable and may lead to wrong conclusions. In addition, the knowledge on membranes' durability/stability is poor and thus long-term tests are required with real gaseous mixtures. Therefore, the feasibility of membrane gas separation for biohydrogen purification should be examined under real conditions with raw fermentation gases in long-term experiments.

As a summary, it can be pointed that membrane gas separation could play significant roles in biohydrogen technology and it is advisable to study hydrogen fermentation and separation in parallel, possibly in integrated applications. The Gas Separation Membrane Bioreactors can likely open a door for this purpose.

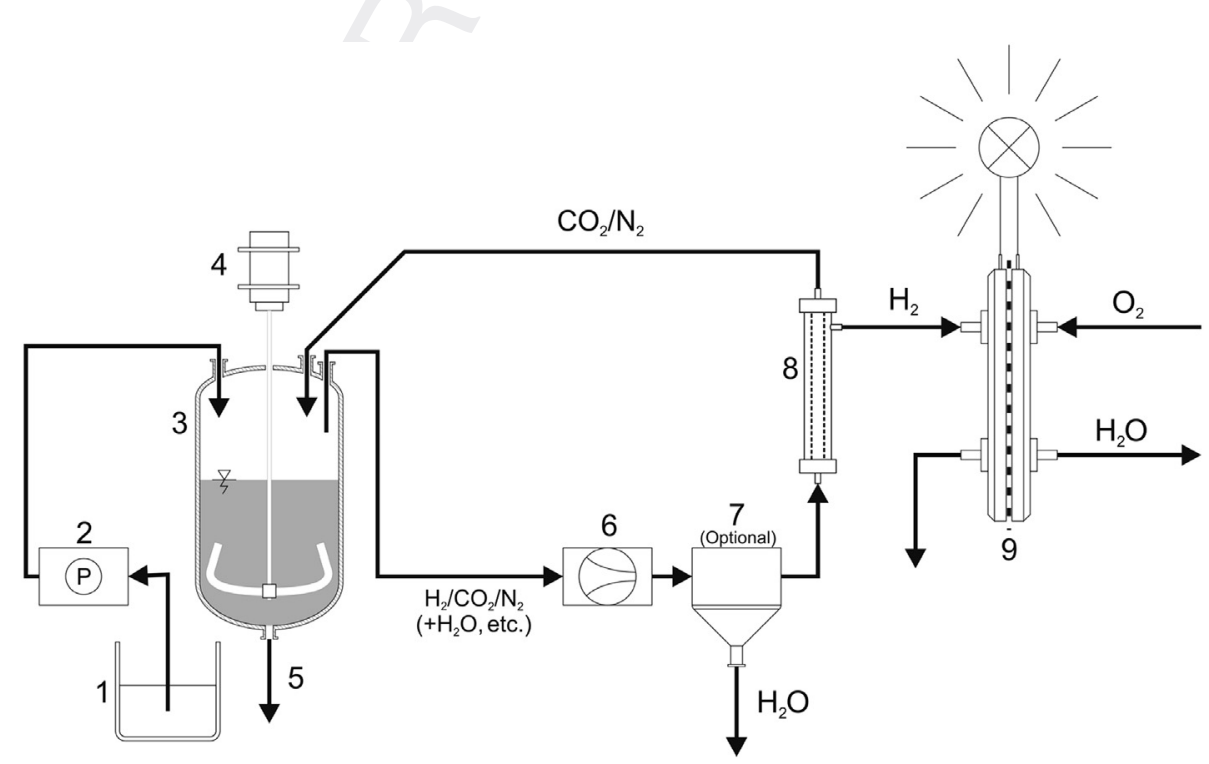

Fig. 1 - The concept of the $e_{\lambda}$ gas ${ }_{\Lambda}$ separation membrane $_{\Lambda}$ bioreactor system. 1: Feed (nutrient) tank; 2: feed (nutrient) pump; 3: bioreactor; 4: stirrer; 5: effluent (spent media); 6: gas compressor; 7: optional humidity control/removal (e.g. condenser); 8: gas separation membrane module; 9: fuel cell. 
In the next sections, the various NPPMs and SILMs showing potential to be built into GSMBRs will be presented and discussed along with the most important operational conditions and their effects.

\section{Non porous, polymeric membranes for GSMBR}

Gas separation applying non-porous, polymeric membranes is a mature technology with practical importance. It has traditionally been used for natural gas conditioning $[5,60]$ and nowadays also receives notable attention from other fields such as biogas, and especially biohydrogen purification, as it will be shown in the following sections.

\subsection{Performance with single gases}

In the last decades, enormous efforts have been made in order to find suitable polymeric membranes for the hydrogen economy and yielded numerous materials with relatively sufficient permeability and selectivity properties. The membranes developed are classified as $\mathrm{H}_{2}$-selective/ $\mathrm{CO}_{2}$-rejective and $\mathrm{CO}_{2}$-selective/ $\mathrm{H}_{2}$-rejective ones. The gas transport through dense polymeric membranes can be described by the solution-diffusion model $[33,52,69]$. Hence, regardless of the membrane used, the selectivity is a result of the diffusivity and solubility differences of the penetrating gases.

The $\mathrm{H}_{2}$-selective membranes are made of so-called glassy polymers sieving molecules based on size and permeating preferentially hydrogen rather than the other - larger and less motile - chemical substances e.g. $\mathrm{CO}_{2}$. On the contrary, the $\mathrm{CO}_{2}$-selective membranes enrich the relatively less soluble hydrogen in the retentate and direct the more condensable compounds to the secondary side of the membrane.

Recently, Shao et al. evaluated in depth the separation efficiencies of various polymeric membranes for $\mathrm{H}_{2}$ concentration [89]. Depending on the material, hydrogen and carbon dioxide permeabilities fluctuated between 2.4-125 and 0.6-84.6 Barrer, respectively. The corresponding $\mathrm{H}_{2} / \mathrm{CO}_{2}$ theoretical selectivities were found as $1.5-5.9$ for the group or $\mathrm{H}_{2}$-selective membranes. As for the $\mathrm{CO}_{2}$-selective class, carbon dioxide and hydrogen permeabilities ranged between 15.3-10700 and 7.9-5800 Barrer, respectively, resulting in ideal $\mathrm{CO}_{2} / \mathrm{H}_{2}$ selectivities of $1.8-11$.

Furthermore, in studies where $\mathrm{H}_{2} / \mathrm{N}_{2}$ separation has been addressed, it was found that nitrogen transport was remarkably slower compared to hydrogen, and consequently it would appear that its elimination is not as difficult issue as of $\mathrm{CO}_{2}$ $[63,64,40,41]$.

It is to notice that a part of the membranes for $\mathrm{H}_{2}$-separation was made of commercial organic matter - not "real designed polymers" - which have originally been engineered for other purposes e.g. natural gas upgrading/sweetening [1]. On the other hand, a large number of high performance, tailor-made polymers have been developed both for $\mathrm{H}_{2}$ - and $\mathrm{CO}_{2}$-selective membranes but presently most of them are too expensive to be commercialized.

Despite the enormous work done it can be concluded that membranes demonstrating both good selectivity and permeability properties are subjects for further investigations. According to Robeson, it appears that a tread-off must be made and higher selectivity can only be achieved at the expense of reduced gas permeation capacity and vice versa. Therefore, the research for more attractive materials should to be continued [82].

\subsection{Performance with mixed gases - the impact of gas composition}

The composition of the gas to be separated is a key factor influencing remarkably the achievable separation efficiency. As it was found, the theoretical selectivities estimated to certain gas pairs were usually higher than the corresponding mixed gas selectivities. However, exclusively the mixed gas studies can help to judge the real appropriateness of the membranes for a given separation task. This is because interactions take place between the gas molecules themselves and/or the gas molecules and the polymer, altering the permeation behavior of the individual gas species. In other words, in multi-compound gaseous mixtures the presence of one gas affects the transport of the other(s), leading eventually to various separation limiting phenomena such as (penetrant induced) plasticization, competitive sorption, concentration polarization, etc. $[19,51,81]$.

Therefore, the permeation properties of the membranes determined in pure gas tests may serve as a "predictive tool" helping to decide whether the selected material/module could or could not have potential for hydrogen enrichment. This implies that only the membranes reflecting sufficient permeability and ideal permselectivity traits might fulfill the separation requirements and should further be investigated with more complex gaseous mixtures. The importance of gas composition is evidenced through the examples taken from the literature, as follows.

Various $\mathrm{CO}_{2}$-selective membranes were tested under mixed gas conditions. Car et al. prepared various PEBAX ${ }^{\circledR} / \mathrm{PEG}$ blend membranes which have been tested both with pure $\left(\mathrm{H}_{2}\right.$, $\left.\mathrm{CO}_{2}, \mathrm{~N}_{2}\right)$ and multi-component gases $\left(\mathrm{H}_{2} / \mathrm{CO}_{2}\right)$, as well. It was observed that the membranes' performances were drastically reduced in the mixed gas experiments regardless of the polymer composition used [16].

In another study, Reijerkerk et al. processed PEBAX ${ }^{\circledR} /$ PEGPDMS membranes and the findings were in agreement with those obtained by Car et al., since the membranes suffered significant loss in separation performance during $\mathrm{H}_{2} / \mathrm{CO}_{2}$ binary gas permeation [80]. Similar conclusions were drawn by Yave et al. using poly(amide-b-ethylene oxide)/polyethylene glycol blend membranes [101]. Interestingly, Chen et al. obtained improved $\mathrm{CO}_{2} / \mathrm{H}_{2}$ mixed selectivities in comparison with the ones measured in pure gas tests using various PEO based membranes. The significant - more than two-fold increment was explained by the decreased permeability of $\mathrm{H}_{2}$ when contacting the special structure polymers with the gas mixture [20].

Furthermore, there are also reports about the behavior of $\mathrm{H}_{2}$-selective membranes during mixed gas permeation. David et al. have conducted comprehensive investigations on polyimide $\left(\right.$ Matrimid $^{\circledR}$ ) membranes [28,29]. In these studies, it was revealed that the $\mathrm{H}_{2} / \mathrm{CO}_{2}$ separation factor has considerably 
decreased under each experimental condition. Moreover, not only binary $\mathrm{H}_{2} / \mathrm{CO}_{2}$ but ternary $\mathrm{H}_{2} / \mathrm{CO}_{2} / \mathrm{N}_{2}$ mixtures were also prepared and used. The output data indicated that $\mathrm{H}_{2}$ transport was not affected by the presence of nitrogen, it was only a function of carbon dioxide concentration.

In a recent study by our group, a commercial polyimide membrane module was subjected to biohydrogen concentration. When the membrane was tested with $\mathrm{H}_{2} / \mathrm{CO}_{2}$ mixture containing 55 vol\% $\mathrm{H}_{2}$ and 45 vol\% $\mathrm{CO}_{2}$ the selectivity has remarkably fallen compared to those measured under ideal conditions [6].

During membrane gas separation, the phenomenon of plasticization commonly occurs and may be a restrictive factor. It is a consequence of plasticizing molecule (e.g. $\mathrm{CO}_{2}$ ) content in the target gas mixture to be separated and can drastically change the membrane's performance $[97,99]$. Briefly, the plasticizer agent - due to its special sorption/condensability features - modifies the polymer structure and hence the permeation rate of all, but especially the "slowly" moving (notplasticizing) compounds present. In other words, plasticization reduces the gas transport resistance of the membranes, leading to higher permeability of all the gas species and hence generally causing depressed selectivity. It is typical for both glassy and rubbery membranes, but has greater impact on the former ones which separate components based on their diffusion difference, meanwhile the members of the latter category rely on distinct solubility properties rather than diffusivity [81]. A couple of approaches have been proposed in order to avoid plasticization as listed in Table 1.

Additionally to the example in Table 1, Hasbullah et al. investigated the permeance properties of pure $\mathrm{H}_{2}, \mathrm{CO}_{2}$ and $\mathrm{N}_{2}$ in membranes made of polyaniline derivative. It has come to light that the fabricated hollow fiber membranes could more effectively resist plasticization compared to other polymers e.g. polyetherimide, polysulfone, polycarbonate and polyestercarbonate [38].

Concerning the issue of membrane plasticization, the research by Lin et al. is also noteworthy. In recent years, they have been developing membranes for hydrogen purification and found that the rubbery, cross-linked poly(ethylene oxide) materials showed viability to remove $\mathrm{CO}_{2}$ from $\mathrm{CO}_{2} / \mathrm{H}_{2}$ mixtures. It was reported that the plasticization of the membrane - attributed to $\mathrm{CO}_{2}$ content - aided the separation, especially at lower temperatures and higher partial pressures of carbon

\section{Table 1 - Few examples for strategies to avoid plasticization effect in non-porous, polymeric} membranes.

\begin{tabular}{ll}
\hline Strategy & \multicolumn{1}{c}{ Reference } \\
\hline Thermal treatment & Kawakami et al. [46] \\
Chemical cross linking & Choi et al. [21] \\
& Lin et al. [59] \\
& Tin et al. [94] \\
& Car et al. [16] \\
Polymer blending & Khan et al. [48] \\
& Reijerkerk et al. [80,81] \\
& Yave et al. [101] \\
\hline
\end{tabular}

dioxide. Moreover, the results revealed that the membranes retained their favorable properties even when additional compounds e.g. $\mathrm{H}_{2} \mathrm{~S}$ and moisture were present [59]. Such findings are highly valuable since beside the main of the gas mixture constituents $\left(\mathrm{H}_{2}, \mathrm{CO}_{2}, \mathrm{~N}_{2}\right)$ evolved during biohydrogen fermentation, certain trace compounds (e.g. $\mathrm{H}_{2} \mathrm{~S}$ ) and humidity could naturally be present and need to be taken into account. These impurities might have considerably influence on membrane's behavior and stability/durability, which must carefully be understood in order to synthesize and/or select appropriate polymeric membranes for (in situ) biohydrogen recovery. Even the membranes perform promisingly with dry binary and ternary gas streams it is not evident that they can also reliably work with wetted feeds.

Water vapor has special characteristics (small size, hydrogen bonding affinity) providing its unique permeation ability. Moisture is strongly condensable and can extremely change the transport of all the compounds present in the mixture [19]. It could be responsible for membrane swelling, (moisture induced) plasticization and also competitive sorption can occur while the gas species compete for the absorption sites in the microvoids existing between the polymer chains in the membrane matrix. Moreover, as it was found, water molecules can form so-called clusters by linking together through hydrogen bounds in hydrophobic and slightly hydrophilic polymers. Such water domains can slow down the permeation of the other gaseous compounds since moving these clusters may act as spatial obstacles $[8,19]$. In other words, water content can increase the mass transfer resistance of the membrane.

In a research carried out by Wang et al. $\mathrm{H}_{2}$ and $\mathrm{CO}_{2}$ permeations were investigated in pure, dry-mixed and wetmixed gas experiments, as well. It has turned out that the surface modified polyimide membranes provided the best selectivity when single gases were used followed by the dryand wet-binary $\mathrm{H}_{2} / \mathrm{CO}_{2}$ mixtures [98]. Despite the importance of humidity, the number of studies discussing its effect on gas separation using non-porous, polymeric membranes is limited and most of them have been performed by applying gas mixtures containing no hydrogen. Therefore, this area can be a subject of future studies and represent an important topic for "real case" biohydrogen purification. If remarkable performance loss of the membranes occurs due to the humidity content then it should be removed, practically condensed prior to feeding the raw fermentation gases to the membrane module.

Getting rid of hydrogen sulfide is of high importance in biohydrogen conditioning. The concentration of this chemical substance is usually in the range of some hundred "ppm", produced as a result of the microbial decomposition of proteins and amino acids with sulfur content. It is a polar and condensable species, capable to form hydrogen bounding and can be characterized by a corrosive nature. Thus, it is reasonably harmful to the end-use technology of biohydrogen (e.g. fuel cells) and - depending on the toughness of the material - it may cause undesired changes in the polymer's structure leading to reduced separation performance and shortened lifetime. However, only few researches can be found on the desulphurization of gaseous mixtures with biological origin using non-porous, polymeric membranes. 
Harasimowicz et al. employed commercial polyimide membrane to upgrade biogas with special focus on hydrogensulfide elimination. They revealed that the membrane module performed satisfactory with different model mixtures comprising $\mathrm{CH}_{4}, \mathrm{CO}_{2}$ and $\mathrm{H}_{2} \mathrm{~S}$. In their study the polyimide membrane reflected good permeability to $\mathrm{H}_{2} \mathrm{~S}$ but its removal efficiency was highly dependent on the separation conditions [37]. Although the results indicate that membrane gas separation is a possible way for biogas processing, its feasibility for the biohydrogen technology must be determined with real gas samples taken from the headspace of anaerobic hydrogen producing bioreactors. Further evaluation on the effect of hydrogen-sulfide using polymeric membranes can be extracted from the literature related to natural gas sweetening $[36,95]$. In another example, Vaughn et al. synthesized novel polyamide-imide polymer membrane for natural gas treatment with special regard to aggressive gas - such as $\mathrm{H}_{2} \mathrm{~S}-$ separation. Summarizing the experiences, $\mathrm{H}_{2} \mathrm{~S}$ was described as a potentially plasticizing chemical, and its effect can be stronger than that of $\mathrm{CO}_{2}$. Moreover, it was indicated that hydrogen sulfide content affected $\mathrm{CO}_{2}$ permeation due to competitive sorption due to the higher affinity of $\mathrm{H}_{2} \mathrm{~S}$ to the sorption sites located in the microvoids of the polymer. This phenomenon has reduced the solubility and flux of other gases (that was more pronounced for $\mathrm{CO}_{2}$ ), causing depressed $\mathrm{CO}_{2} / \mathrm{CH}_{4}$ selectivities over a wide range of feed pressures [96].

As it was discussed so far, minor contaminants can have noticeable influence on the polymeric membrane's behavior. However, their combined effects might be different from those determined for the individual compounds. Therefore, this is another reason for the necessity of testing the membranes directly with raw fermentation gas mixtures.

Furthermore, exposing the membranes to highly interacting compounds (e.g. $\mathrm{CO}_{2}, \mathrm{H}_{2} \mathrm{~S}$ ) could provide data not only about the permeability and selectivity values but also about the reversible/irreversible changes taking place in the polymer structure and hence, it can be a possible way to determine the membrane's stability/durability [96].

In a research by Scholes et al. the impact of $\mathrm{H}_{2} \mathrm{~S}$ and water content on the characteristics of PDMS membrane was sought [85]. It was concluded that when $\mathrm{H}_{2} \mathrm{~S}$ and $\mathrm{CO}_{2}$ permeated simultaneously through the membrane $\mathrm{CO}_{2}$ permeability has decreased significantly. On the other hand, the presence of $\mathrm{H}_{2} \mathrm{~S}$ tended to slightly increase $\mathrm{N}_{2}$ permeation rate. It was also pointed out that both $\mathrm{CO}_{2}$ and $\mathrm{N}_{2}$ transport were affected by moisture in a manner that the higher the water content the smaller the flux could be measured. It was also elucidated that water preferentially dominated the regions of the PDMS matrix alone rather than be mixed with the other gaseous substances and hence, limited the available volume in the polymer for $\mathrm{CO}_{2}$ and $\mathrm{N}_{2}$ permeation causing hindered gas transport.

Despite the valuable findings presented, further evaluation is essential on that topic since hydrogen was typically not presented in the mixtures studied.

It is worth to note about some future directions in the development of non-porous, polymeric gas separation membranes. The first to mention is the group of the mixed-matrix membranes which combines the dense polymers with inorganic materials $[3,89,100]$. These hybrid membranes reflect some advantages in comparison with their pure polymeric counterparts and have been developed in order to overcome their separation limitations. Taking into account the recent research progress in that field, zeolite, silica, carbon nanotubes and metal(nanoparticles) (e.g. Pd) are the most potential inorganic materials to be integrated with an NPPM that serves as incorporation matrix $[2,9,23,47,50,91]$. The possible benefits of these membranes can be their improved mechanical endurance against harsh conditions and significantly enhanced separation characteristics. Although such membranes are innovative, they will not leave the laboratory-scale unless some apparent bottlenecks such as high cost demand, unstable polymers at elevated temperatures, poor adhesion between the inorganic and organic phases, etc. are not solved $[3,89]$.

Another opportunity to obtain more attractive hydrogen separation membranes or in other word, a possible way forward is the development and use of thermally rearranged polymers. These materials comprise aromatic polymers interconnected with heterocyclic rings, e.g. polybenzoxazoles and polybenzothiazoles. Such materials express superior thermal and chemical resistance and therefore, may be used under harsh separation circumstances e.g. to selectively enrich hydrogen from steam reformers' off-gas [76].

Park et al. studied thermally rearranged polymers for gas separation purposes. They reported about the difficulties of membranes processing and fabrication as well as they concluded that these kinds of artificial polymers showed impressive gas separation performances both in terms of selectivity and permeability. These traits were explained by the special microstructure of the membranes that could be fine-tuned e.g. by heat treatment. Moreover, it was found that the thermally rearranged membranes could successfully withstand plasticization during $\mathrm{CO}_{2} / \mathrm{CH}_{4}$ separation up to 20 atm carbon-dioxide partial pressure at $35^{\circ} \mathrm{C}[75,76]$.

Besides, an alternative and highly promising path is to employ polymer-based organic microporous materials, or in other words, the Polymers of Intrinsic Microporosity (PIMs) $[13,67]$. These matters behave similarly to microporous materials in solid state and their non-cross linked, soluble members could potentially be applied for gas separation tasks $[14,15]$.

\subsection{Effect of operational conditions on membrane performance - issues of pressure, temperature and stage cut}

In previous sections the impact of gas composition on membrane's behavior was detailed. However, there are other factors governing the separation process for a given membrane module made of a certain material: these are the applied the operational conditions (feed pressure, temperature, stage cut).

Gas separation employing non-porous, polymeric membranes is basically a concentration-driven technology but the (partial) pressure difference/ratio between the feed and permeate sides plays also a key role $[52,69]$. In theory, the higher the (partial) pressure ratio the greater the flux and selectivity can be obtained.

Pressure issue is important from an additional point of view. As specified above, a few material-design related approaches were suggested to overcome susceptibility to plasticization. 
Nevertheless, the responsiveness of membrane materials to penetrant (e.g. $\mathrm{CO}_{2}$ ) induced plasticization is not independent of the operational conditions. In fact, it is mainly associated with moderate and higher feed pressure (fugacities) regions $[16,80]$. Therefore, it possibly does not represent a notable issue during biohydrogen separation since $\mathrm{H}_{2}$ is formed at nearly ambient pressures ( $\sim 1 \mathrm{~atm})$ and its high compression would consume a large part of the chemical energy stored in that. On the other hand, it is beneficial to maintain as high pressure ratio as possible across the membrane because of it determines the driving force and hence strongly affects the process efficiency $[52,69]$.

Theoretically, there is another opportunity to improve the driving force beyond manipulating feed pressure. This is the application of vacuum on the permeate side. At least a slightly under-pressurized secondary side of the membrane module could ensure improved transmembrane pressure ratio without the need of feed compression - and lead to enhanced gas transport through the membrane. Although vacuum seems attractive, it might not be suitable when scaling a labsize technology up since the cost of the increased performance is the multiplied volume of the gas to be handled. This can represent a practical limitation at industrial facilities. Consequently, the applicability of vacuum should carefully be addressed.

David et al. used membranes made of polyimide (Matrimid ${ }^{\circledR}$ ) and found that the achievable permeabilities and mixed-gas selectivities for $\mathrm{H}_{2} / \mathrm{CO}_{2}$ binary mixtures were not only the function of feed pressure (fugacity) itself but the composition of the gas to be separated also played a significant role [29]. This implies that the effects of feed pressure and gas composition can be cross-dependent and therefore the feed pressure applied should be chosen by considering the gas composition. Hence, a trade-off might be necessary in terms of pressure conditions due to multiple reasons in order to attain optimal purification efficiency.

Studies discussing the effect of feed pressure (fugacity) on various membranes' performances have been published by several authors and presented in Table 2.

Beside pressure, temperature is also a factor during gas separation using non-porous, polymeric membranes since it determines the permeability and selectivity properties. Basically, the $\mathrm{H}_{2}$ - and $\mathrm{CO}_{2}$-selective membranes favor distinct operational temperatures. The formers are usually operated at moderate or slightly elevated temperature, meanwhile the

\begin{tabular}{ll}
$\begin{array}{l}\text { Table } 2 \text { - Studies dealing with the effect of pressure and } \\
\text { temperature on non-porous, polymeric membrane's } \\
\text { behavior. }\end{array}$ \\
$\begin{array}{ll}\text { Papers discussing on } \\
\text { pressure's effect }\end{array}$ & $\begin{array}{l}\text { Papers discussing on } \\
\text { temperature's effect }\end{array}$ \\
\hline Car et al. [16] & Car et al. [16] \\
Chua et al. [22] & David et al. [28] \\
David et al. [28,29] & Husken et al. [41] \\
Lin and Freeman [57] & Lin and Freeman [57] \\
Reijerkerk et al. [80,81] & Reijerkerk et al. [81] \\
Scholes et al. [85] & Rowe et al. [84] \\
Talakesh et al. [92] & Scholes et al. [85] \\
\hline
\end{tabular}

latter ones require relatively lower temperatures (even below the normal freezing point of water) for efficient separation [58]. This is attributed to the fact that $\mathrm{H}_{2}$-selective, glassy polymers, as mentioned earlier, separate gases based on diffusivity (molecule size) differences, while $\mathrm{CO}_{2}$-selective, rubbery materials achieve separation through variances in solubility of the permeating molecules. Temperature displays reverse effect on gas diffusivity and solubility. Elevating/ decreasing the temperature enhances/inhibits gas diffusion, while on the other hand, reduces/increases solubility in a significant manner. Additionally, temperature changes the polymer's structure and the corresponding features such as flexibility and motion of the polymer chains, free volume, etc. that significantly affect gas transport.

In general, for non-porous, polymeric membranes an permeability and temperature, indicating that the higher the temperature the greater the flux is expected for pure gases [79]. However, theoretical and real selectivities could either be depressed or improved with temperature. It is important to note that the observable impacts of temperature on the main characteristics of membrane are material specific in a certain degree and might vary from polymer to polymer. This supposes a possible trade-off in separation temperature so as to keep balance between permeability and the obtainable gas (product) purity. Articles dealing with the influence of temperature on membranes' performances have recently been reported, some examples are indicated in Table 3.

In addition to the pressure and temperature, stage-cut is also an important process variable during multi-compound gas separation and gives how much of the gas mixture introduced to the membrane as a feed is taken as permeate. Its value highly influences the achievable purification efficiency since the final concentration of the target compound(s) both in permeate and retentate fractions is stage-cut dependent [4]. Similar conclusions were drawn in our recent study, as well [6].

Moreover, the proper selection of stage-cut can help to reduce concentration polarization that is a possible threat during the separation. In brief, it occurs when excess molecules are accumulated in a nearby, boundary layer to the membrane's surface where the concentration of the fastly-permeating component(s) is reduced, meanwhile that is of the lesspermeable gas(es) is increased compared to the bulk phase. Therefore, a concentration gradient is generated close to the membrane's surface that reduces the driving force (concentration difference) between the feed and permeate sides of the membrane and consequently decreases both the permeability and selectivity [62]. For example, when the ratio of permeate in the feed flows is low, only a limited portion of the inlet gas passes through the membrane. Thus, in that case, the change in gas composition on the membrane's surface might be neglected and concentration polarization can be restricted. Nevertheless, there are compounds such as $\mathrm{H}_{2} \mathrm{O}$ potentially causing concentration polarization even at low stage-cut values [19].

This is another fact that proves the membrane's performance for biohydrogen recovery should be assessed not only under "ideal" circumstances but also with "real" gas mixtures, representing much more complex matrices to be handled. Arrhenius-type relationship can be established between gas 
Table 3 - Examples for mixed $\left(\mathrm{H}_{2} / \mathrm{CO}_{2}\right)$ gas separation studies using non-porous, polymeric membranes.

Membrane Operational conditions material

\begin{tabular}{|c|c|c|c|c|c|c|c|c|c|}
\hline \multirow{3}{*}{ mat } & & & & & & & & & \\
\hline & \multicolumn{2}{|c|}{$\begin{array}{l}\text { Feed gas } \\
\text { composition }\end{array}$} & \multirow[t]{2}{*}{$\begin{array}{l}\text { Feed } \\
\text { pressure }\end{array}$} & \multirow[t]{2}{*}{ Temperature } & \multicolumn{3}{|c|}{ Gas flux } & \multirow[t]{2}{*}{$\begin{array}{c}\text { Real } \\
\text { selectivity }\end{array}$} & \\
\hline & $\begin{array}{c}\mathrm{H}_{2} \\
\text { (vol\%) }\end{array}$ & $\begin{array}{c}\mathrm{CO}_{2} \\
\text { (vol\%) }\end{array}$ & & & $\mathrm{H}_{2}$ & $\mathrm{CO}_{2}$ & Overall & & \\
\hline $\begin{array}{l}\text { PEBAX }^{\circledR} / \text { PEG } \\
\text { blends }\end{array}$ & 50 & 50 & $7-20$ bar & $293 \mathrm{~K}$ & n.s. & n.s. & $0.13-0.31^{a}$ & $8-9.5$ & Car et al. [16] \\
\hline $\begin{array}{l}\text { PEBAX }^{\circledR} / \text { PEG-PDMS } \\
\text { blends }\end{array}$ & 30 & 70 & $6-35$ bar & $308 \mathrm{~K}$ & n.s. & n.s. & n.s. & $9-10$ & Reijerkerk et al. [80] \\
\hline PEBAX $^{\circledR} /$ PEG blends & 50 & 50 & 5 bar & $293 \mathrm{~K}$ & $1.5-2.5^{f}$ & $13-31^{\mathrm{f}}$ & n.s. & $8.1-9.6$ & Yave et al. [101] \\
\hline PEO-PI copolymers & 50 & 50 & $2 \mathrm{~atm}$ & $308 \mathrm{~K}$ & $5-7.9^{\mathrm{b}}$ & $\begin{array}{l}179.3^{\mathrm{b}} \\
\text { (highest) }\end{array}$ & n.s. & $21-22.7$ & Chen et al. [20] \\
\hline PI (Matrimid ${ }^{\circledR}$ 5218) & 10 & 90 & 4-6 bar & $303 \mathrm{~K}$ & $10-17^{c}$ & $4.1-5.2^{c}$ & n.s. & $2.7-3$ & David et al. [28] \\
\hline PI (Matrimid ${ }^{\circledR} 9725$ ) & $20-80$ & $80-20$ & $2-10$ bar & $303 \mathrm{~K}$ & $36-48^{d}$ & $9-12^{d}$ & n.s. & $3.1-4.6$ & David et al. [29] \\
\hline $\begin{array}{l}\text { PI (commercial UBE } \\
\text { membrane) }\end{array}$ & 55 & 45 & $1.1-1.8 \mathrm{bar}$ & $310 \mathrm{~K}$ & n.s. & n.s. & $3.7-10.5^{\mathrm{e}}$ & $1.34-1.56$ & Bakonyi et al. [6] \\
\hline $\begin{array}{l}\text { Cross-linked PEG } \\
\text { copolymer }\end{array}$ & 20 & 80 & $17 \mathrm{~atm}^{\mathrm{g}}$ & $308 \mathrm{~K}$ & n.s. & n.s. & n.s. & 9.4 & Lin et al. [59] \\
\hline 6FDA-durene PI & 50 & 50 & $7 \mathrm{~atm}$ & $308 \mathrm{~K}$ & $14-303^{b}$ & $0.8-407^{b}$ & n.s. & $0.75-77.1$ & Wang et al. [98] \\
\hline \multicolumn{10}{|c|}{$\begin{array}{l}\text { n.s.: not specified. } \\
\text { a }\left(\mathrm{m}^{3} / \mathrm{m}^{2} \mathrm{~h} \text { bar). }\right. \\
\text { b Barrer. } \\
\text { c }\left(\mathrm{m}^{3}(\mathrm{STP}) \mathrm{m} \mathrm{m}^{-2} \mathrm{~s}^{-1} \mathrm{kPa}^{-1}\right) 10^{14} \text {. } \\
\text { d }\left(\mathrm{m}^{3}(\mathrm{STP}) \mathrm{m} \mathrm{m}^{-2} \mathrm{~s}^{-1} \mathrm{kPa}^{-1}\right) 10^{8} \text {. } \\
\text { e } \mathrm{dm}^{3}(\mathrm{STP}) \mathrm{min}^{-1} \text {. } \\
\text { f }\left(\mathrm{m}^{3} / \mathrm{m}^{2} \mathrm{~h} \text { bar }\right) 10^{2} \text {. } \\
\text { g Partial pressure of } \mathrm{CO}_{2} \text {. }\end{array}$} \\
\hline
\end{tabular}

\section{Ionic liquid membranes for GSMBR}

Ionic liquids (ILs) are wide-spread materials with industrial recognition and have recently been used at various fields of interest including gas separation, as well [74]. They are salts with a melting point below $100{ }^{\circ} \mathrm{C}$ and basically composed of an organic cation and an inorganic anion which can be varied according to the respective task of separation. Therefore ILs can be called as tailor-made chemicals [35] and being employed as substitutes to the traditional organic solvents in membrane, more specifically in liquid membrane technology applied for gas separation due to their fine-tunable properties and negligible tension (non-volatile nature) preventing solvent losses.

The IL based liquid membranes combine porous polymeric membranes and ionic liquids which thus form together nonporous membranes and refer to the term of "Supported Ionic Liquid Membrane", abbreviated as SILM [65].

SILMs employing a large number of ILs - mostly Room Temperature Ionic Liquids (RTIL) - have demonstrated appropriate qualities for the separation of $\mathrm{H}_{2}, \mathrm{CO}_{2}, \mathrm{~N}_{2}$, as well.

\subsection{Performance with single and mixed gases - gas composition effect}

SILMs for hydrogen enrichment purposes have been extensively studied. Neves et al. investigated the appropriateness of various imidazolium-cation based RTILs for biohydrogen concentration using PVDF membrane as support material in pure gas tests [72]. Based on the permeability values determined, it was revealed that the membranes allowed the gases to permeate in the following order: $\mathrm{CO}_{2}>\mathrm{H}_{2}>\mathrm{N}_{2}$. It has also been shown that the length of the cation present influenced the ideal selectivity $\left(\alpha_{i / j}\right)$ for $\mathrm{CO}_{2} / \mathrm{H}_{2}\left(5<\alpha_{\mathrm{CO}_{2} / \mathrm{H}_{2}}<8\right)$. However, it has not affected $\mathrm{H}_{2} / \mathrm{N}_{2}$ selectivity $\left(\alpha_{\mathrm{H}_{2} / \mathrm{N}_{2}}=4\right)$. On the other hand, it was demonstrated that altering the anion coupled with the imidazolium-based cation could change the overall behavior of the membrane $\left(6<\alpha_{\mathrm{CO}_{2} / \mathrm{H}_{2}}<11 ; 3<\alpha_{\mathrm{H}_{2} / \mathrm{N}_{2}}<4\right)$.

Cserjési et al. incorporated VACEM type ionic liquids and microporous PVDF membranes in order to separate hydrogen from carbon dioxide and nitrogen. As it was found, the rate of $\mathrm{CO}_{2}$ permeation was the highest by far resulting in decent $\mathrm{CO}_{2} / \mathrm{H}_{2}$ theoretical selectivity [25].

In a more recent research by Cserjési et al., 12 different types of ionic liquids were employed for gas separation. It was reported that not all of the ILs were suitable for membrane fabrication because some of them destroyed the PVDF support matrix. Nevertheless, those which were found applicable possessed potential toward $\mathrm{H}_{2}$ purification. Theoretical $\mathrm{CO}_{2} /$ $\mathrm{H}_{2}$ and $\mathrm{H}_{2} / \mathrm{N}_{2}$ selectivities ranged between s $_{-}-13$ and 1.7-7.7, respectively [26].

Neves et al. determined the permeation properties of $\mathrm{H}_{2}$, $\mathrm{CO}_{2}$ and $\mathrm{N}_{2}$ for membranes prepared with ionic liquids containing methyl-imidazolium cations (differing in side chain length) and various anion groups. Two different (hydrophilic, hydrophobic) poly(vinylidene fluoride) membranes were used as immobilization materials. As it was observed, the increase in the alkyl chain length of the cation returned in enhanced gas fluxes. The permeabilities of the gases could be ordered as 
$\mathrm{CO}_{2}>\mathrm{H}_{2}>\mathrm{N}_{2}$. Furthermore, it was found that the anion and its viscosity also had great impact on permeability. Regardless of the IL's structure, the membranes were typically selective for $\mathrm{CO}_{2}$ rather than for $\mathrm{H}_{2}$ and $\mathrm{N}_{2}$ [73]. In a succeeding work by the same research group, Ion-jelly ${ }^{\circledR}$ (combination of ionic liquid and gelatin) membranes were prepared for $\mathrm{H}_{2}, \mathrm{CO}_{2}$ and $\mathrm{N}_{2}$ separation [24]. The calculated permeabilities and ideal selectivity values remained in the same order of magnitude as in the previous study [73] but lower ideal selectivities could be achieved.

In another research, composite membranes were made of fairly permeable glassy fluorine-containing polyimide and methyl-imidazolium type ionic liquid. It has turned out that the ionic liquid to membrane mass ratio played a key role in the separation of gases due to IL domain formation. Accordingly, the permeability of all the gases including $\mathrm{H}_{2}, \mathrm{CO}_{2}$ and $\mathrm{N}_{2}$ was fluctuated and the highest $\mathrm{CO}_{2} / \mathrm{H}_{2}$ theoretical selectivity could be obtained by the membrane containing the highest amount of IL (81 wt.\%) [45].

Friess et al. investigated the gas transport properties of ionic liquid polymer gel membranes with high ionic liquid content. The IL used was a methyl-imidazolium cation based one. The outcomes evidenced that increasing the IL content up to 80 wt.\% significantly enhanced the permeabilities, however, the degree of increment was gas specific. The ideal selectivities were computed for the gas pairs tested and it was seen that $\mathrm{CO}_{2}$ could more effectively be separated from $\mathrm{H}_{2}$ when higher amount of IL was used for to construct the membrane. The $\mathrm{CO}_{2}$ permeability exceeded 500 Barrer and $\mathrm{CO}_{2} / \mathrm{H}_{2}$ selectivity was higher than 10 at $80 \mathrm{wt} . \%$ ionic liquid content. On the other hand, the membrane's behavior in terms of $\mathrm{H}_{2} / \mathrm{N}_{2}$ selectivity was contradictory since the higher the IL content the lower the separation factor could be achieved. When the maximum amount of IL was applied, it decreased to $\sim 2.5$ [31].

Carlisle et al. synthesized a series of cross-linked poly(vinylimidazolium)-RTIL gel membranes with various loadings of mono-, difunctional and non-polymerizable IL monomers. Subsequently, the membranes' features were determined with pure gases. It was shown that $\mathrm{CO}_{2}$ permeability has remarkably increased with free RTIL mass ratio and resulted in improved ideal $\mathrm{CO}_{2} / \mathrm{H}_{2}$ selectivity. The best performance was observed at $75 \mathrm{wt}$.\% free RTIL content where impressive $\mathrm{CO}_{2}$ permeability (>500 Barrer) and $\mathrm{CO}_{2} / \mathrm{H}_{2}$ selectivity (12) could be attained. Moreover, it was found that decreasing the amount of cross-linking monomer yielded somewhat enhanced $\mathrm{CO}_{2} / \mathrm{H}_{2}$ permselectivity. Finally, the experimental data indicated that changing the length or chemical composition of the mono-functional monomers had only marginal impact on the separation process [17].

Some studies dealing with mixed gas permeation using SILMs are available but it is important to note that in the vast majority of the cases where $\mathrm{CO}_{2}$ separation was focused, $\mathrm{H}_{2}$ was not taken into account during the experiments. Nevertheless, the research outcomes can represent useful platform for future design considerations.

The SILMs engineered by Cserjési et al. exhibited decreased permeabilities by $19-15 \%$ during ternary $\mathrm{H}_{2} / \mathrm{CO}_{2} / \mathrm{N}_{2}$ gas separation compared to the single gas measurements which was explained by the interactions between the molecules [25].
Scovazzo et al. reported on the performance of SILMs applying imidazolium type ionic liquids. It was demonstrated that the supported ionic liquid membranes not only outperformed the conventional polymers for $\mathrm{CO}_{2} / \mathrm{N}_{2}$ and $\mathrm{CO}_{2} / \mathrm{CH}_{4}$ separation during pure gas tests but it was also found that theoretical and mixed gas selectivities remained comparable for the latter gas pair. On the contrary, $\mathrm{CO}_{2} / \mathrm{N}_{2}$ mixed gas selectivities were not given due to the extremely low flux of $\mathrm{N}_{2}$ that made the corresponding experimental values unreliable [87].

Neves et al. carried out tests with binary $\mathrm{CO}_{2} / \mathrm{N}_{2}$ and $\mathrm{CH}_{4} /$ $\mathrm{CO}_{2}$ mixtures. It was presented that regardless of the SILMs used mixed gas selectivities for both gas couples were lower than the ideal values obtained with pure gases. However, the difference between them was not considerable, which is an important conclusion [73].

These results well-agreed with the findings of $\mathrm{Gu}$ et al. who focused on $\mathrm{CO}_{2}$ separation by two block copolymer ion gel systems using methyl-imidazolium cation based ionic liquid [EMIM][TFSA] as monomer to be polymerized and PVDF membrane as support. It has clearly been showed that under certain conditions - the ideal and mixed gas selectivities for $\mathrm{CO}_{2} / \mathrm{N}_{2}$ and $\mathrm{CO}_{2} / \mathrm{CH}_{4}$ were only hardly distinguishable (Gu et al., 2012).

The given examples evidence that the various kinds of SILMs have strong potential for gas separation since in comparison with the above-discussed non-porous, polymeric membranes their selectivities are not remarkably changed when being exposed to multi-compound gaseous mixtures.

However, it must be pointed out that this behavior is highly dependent on the operational (separation) conditions, as discussed in the next section. It is consistent from the literature that the SILMs have generally been exposed to only gently over-pressurized gas streams, where membranes are expected to be less sensitive to penetrant (e.g. $\mathrm{CO}_{2}$ ) induced plasticization. Similarly to the conventional, non-porous polymeric membranes, selectivity loss might occur in the higher feed (partial) pressure regions in the case of SILMs, as well.

Beside the studies dealing with $\mathrm{H}_{2}, \mathrm{CO}_{2}$ and $\mathrm{N}_{2}$, a limited number of articles discuss on the effects of trace compounds - water vapor and $\mathrm{H}_{2} \mathrm{~S}$ - present in the raw, hydrogen containing fermentation gases.

Water content in ionic liquids is an important issue, since it is capable to modify the physical properties (e.g. density, viscosity) of the IL employed [43] that could in turn either improve or depress the separation performance and stability of the membranes.

Scovazzo et al. conducted research on SILMs made of ionic liquids containing anions other than $\left[\mathrm{PF}_{6}\right]^{-}$to separate $\mathrm{CO}_{2}, \mathrm{~N}_{2}$ and $\mathrm{CH}_{4}$. In terms of water content, the illustrated experimental results revealed that good $\mathrm{CO}_{2}$ permeation could be observed even with humidified gas streams [86].

Zhao et al. investigated the role of water content on the

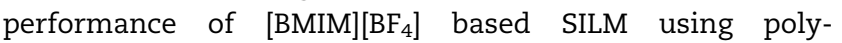
ethersulfone support matrix for $\mathrm{CO}_{2} / \mathrm{N}_{2}$ separation. From both the theoretical and experimental results it could be drawn that water content influenced ionic liquid-water interaction as well as $\mathrm{CO}_{2}$ and $\mathrm{N}_{2}$ permeation by changing their solubility and diffusivity properties, though its extent was dependent on 
the gas species. In addition, water presumably caused liquid loss of the membranes which was more pronounced at higher water concentrations. Nevertheless, it was demonstrated that the presence of at least a small portion of water could enhance selectivity, while after reaching a certain level it reduced the separation efficiency. Furthermore, tests indicated that membrane stability was not independent of the water content, without which they could not reliably operate for a long time [104].

Neves et al. compared the permeabilities of $\mathrm{CO}_{2}, \mathrm{~N}_{2}, \mathrm{CH}_{4}$ gases under both dry and humidified conditions for [ $\left.\mathrm{C}_{4} \mathrm{MIM}\right]$ $\left[\mathrm{PF}_{6}\right], \quad\left[\mathrm{C}_{4} \mathrm{MIM}\right]\left[\mathrm{Tf}_{2} \mathrm{~N}\right]$, and $\left[\mathrm{C}_{8} \mathrm{MIM}\right]\left[\mathrm{PF}_{6}\right]$ ionic liquid based membranes. As it was displayed the permeation rates of all the gases were enhanced with increasing moisture content, however, selectivity has decreased. It was assumed that water clusters were formed in the ILs leading to changes in the transmembrane gas transport. In other words, humidity lowered the ionic liquids' viscosities and made the SILMs less selective. Moreover, it was suggested that the increase in permeability under wetted circumstances was connected with the solubility properties of gas species in the ILs. Therefore, the transport of the less soluble (and more diffusive) compounds was approximately 2-3 fold more affected in comparison with $\mathrm{CO}_{2}$. In addition, it has come to light that the hydrophilicity of the IL was also responsible for the variations in permeability and selectivity [73].

As a summary, the moisture content of untreated fermentation gases can play multiple roles and should be taken into account during gas separation using SILMs. It can not only serve as a restricting factor but can also be advantageous to prevent long-term performance loss. However, actions may be required to control water concentration in the gas being introduced to the membrane in order to realize that benefit.

Concerning the application of SILMs for hydrogen sulfide removal the work by Park et al. can be cited, where [BMIM] $\left[\mathrm{BF}_{4}\right]$ ionic liquid was combined with PVDF solid matrix for natural gas upgrading. As it was assessed, the increment in IL content was coupled with a significant improvement in the permeation rates of all the gases with special regard to $\mathrm{H}_{2} \mathrm{~S}$ which showed high affinity to the liquid salt. The $\mathrm{H}_{2} \mathrm{~S} /$ $\mathrm{CH}_{4}$ permselectivity $(>200)$ peaked at an IL to carrier material mass ratio of 1.5. Further increase caused selectivity loss which was explained by the plasticization of the PVDF support matrix took place due to the high ionic liquid content [77].

It would appear that supported ionic liquid membranes likely have potential to recover compounds of interest and the complexity of the gaseous mixtures is a factor that remarkably influences the applicability of this technology.

In many cases it was observed that such membranes were able to outperform the conventional non-porous, polymeric membranes according to the upper-bound relationship given by Robeson, which is intended to demonstrate the correlation between the two main characteristics of the membrane, the permeability and selectivity. For more details about the upperlimits of ionic liquid-based gas separation membranes see the review paper by Scovazzo [88].

Although various SILMs have been developed and found to be promising for $\mathrm{CO}_{2}, \mathrm{~N}_{2}, \mathrm{H}_{2} \mathrm{O}$ and $\mathrm{H}_{2} \mathrm{~S}$ removal, the target gas $\mathrm{H}_{2}$ was not involved in the research in many cases.
Therefore, further attempts are essential with raw, $\mathrm{H}_{2}$ containing fermentation gases in order to get a better understanding about the behavior of the membranes under realistic conditions. Furthermore, it is important to point out that beyond the presence of the major $\left(\mathrm{CO}_{2}, \mathrm{~N}_{2}\right)$ and minor $\left(\mathrm{H}_{2} \mathrm{O}\right.$, $\mathrm{H}_{2} \mathrm{~S}$ ) impurities the viability of IL based membranes for gas (biohydrogen) separation is dependent on the operational circumstances (e.g. pressure, temperature), as well.

\subsection{Effects of operational conditions on SILM performance - pressure and temperature dependency}

The mechanism of gas transport through supported ionic liquid membranes is somewhat similar to that of the conventional non-porous, polymeric membranes, indicating that the diffusivity and solubility of the gaseous compounds determine the separation. These parameters are affected by the operational pressure and temperature.

Pressure plays a key role from various aspects in supported ionic liquid membrane technology. One reason beyond the increasing popularity of SILMs for biological gas (e.g. biohydrogen) conditioning is their potential feasibility under lowpressure circumstances, generally up to $2-5$ bars [61]. It is beneficial since good separation properties are expressed nearly to the conditions where biohydrogen production taking place and therefore the need for energy intense compression can be mitigated.

In theory, similarly to the non porous, polymeric membranes the increase in transmembrane pressure gradient is expected to bring higher gas permeability and separation factor due to enhanced driving force. However, improving the pressure ratio above a certain level could cause stability loss of the membranes since the ILs could be vanished from the pores of the support material. In addition, SILMs can be compressed under higher feed pressures. In this case, smaller amounts of ionic liquids can be carried by the porous support material leading to reduced membrane resistance and hence performance loss may occur. Higher pressures can also cause defects or leakages that structurally disrupt the SILM inherently causing decreased gas separation efficiency.

To overcome the instability issues related to conventional SILMs, various techniques have been developed in the recent years. For example, it was demonstrated that using nanofiltration membranes as support materials sufficient capillary binding forces can be provided that help the ionic liquid to stay in the pores even at higher pressure $[32,39]$. The stability and probably the pressure resistance of the SILMs can also be improved by coating the ionic liquids with a dense polymer (e.g. PDMS) film. Such a technique has been proposed for pervaporation membranes but it could equally be suitable for the fabrication of gas separation membranes, as well [42]. Furthermore, the entrapment of ILs in natural gelling agents (e.g. gelatin) has been suggested [24]. Another possibility is the polymerization of ILs since SILMs comprising polymerized ionic liquids can more likely sustain the harsh conditions due to their improved mechanical durability [7,17], Gu et al., 2012, $[44,102]$.

Generally, the pressure limit against which the membrane can stand - called the critical displacement pressure - is dependent on factors such as the size and structure of the 
pores in the support matrix, the interfacial tension of the ILs and the contact angle (Zha et al., 1992, [105]).

In a study by Cserjési et al. it was found that elevated pressures lowered the permeabilities of pure gases $\left(\mathrm{H}_{2}, \mathrm{CO}_{2}\right)$ for certain ILs. The reason for this contradictory behavior remained unclear but the explanation given suggested that the deformation of the pores in the support matrix has occurred and thus the available volume for gas transfer has reduced [26].

Zhao et al. impregnated various (e.g. polyethersulfone (PES), nylon 6 and polyvinylidene fluoride) membranes in [BMIM] $\left[\mathrm{BF}_{4}\right]$ ionic liquid. Subsequently, the mechanism of membrane liquid loss has comprehensively been investigated. It was demonstrated that PES could serve as the most reliable material, however, the results indicated that the increase both in transmembrane pressure ratio and in the pore size of the carrier matrix caused ionic liquid loss and significant decrease in $\mathrm{CO}_{2} / \mathrm{N}_{2}$ selectivity. It was also revealed that the affinity of ionic liquid to the immobilization matrix is a crucial parameter influencing the membrane's stability. The [BMIM] $\left[\mathrm{BF}_{4}\right] / \mathrm{PES}$ membrane was subjected to gas permeation experiments and it was concluded that the permeation rates of all the gases $\left(\mathrm{CO}_{2}, \mathrm{H}_{2}, \mathrm{~N}_{2}\right)$ increasingly changed with feed pressure, while on the other hand, $\mathrm{CO}_{2} / \mathrm{N}_{2}$ and $\mathrm{CO}_{2} / \mathrm{H}_{2}$ ideal selectivities showed a descending trend upon primary-side pressure increase. Interestingly, it was observed that the SILMs have not totally lost their separation performances in spite of the considerable liquid loss at higher pressures. A couple of possible reasons were supposed to elucidate this behavior but further research was suggested in order to confirm the theories [105].

In an earlier work by Zhao et al., the mutual effects of feed pressure and gas humidity were studied. It was found that at certain water content of the gas mixture fed to the membrane, increasing feed pressure could yield higher permeabilities for $\mathrm{CO}_{2}$ and $\mathrm{N}_{2}$ gases [104].

In addition, the pressure issue can be important for aggressive gas removal, as well. In the study by Park et al. it could be seen that $\mathrm{H}_{2} \mathrm{~S}$ was able to permeate across the membrane more effectively along with gradually increasing feed pressure. Therefore, improved removal efficiency was achieved at elevated transmembrane pressure gradient where the SILMs could still withstand the harsh conditions [77].

The effect of temperature has thoroughly been evaluated in many researches. Cserjési et al. have found that the gas permeation through membranes prepared with VACEM-type ionic liquids was accelerated by temperature increase in a statistically significant manner [25]. In their other study, it was illustrated that increase in temperature resulted in an increment of $\mathrm{H}_{2}$ permeabilitiy regardless of the IL used. It was attributed to the change of IL's viscosity that affected the transport properties (e.g. diffusivity) of the gases [26].

Finotello et al. investigated the temperature dependency $\left(25-70^{\circ} \mathrm{C}\right)$ of hydrogen, carbon dioxide, nitrogen and methane permeation in imidazolium-based room temperature ionic liquids at nearly ambient pressure. It was reported that the higher the temperature the greater the gas fluxes and the lower the theoretical selectivities could be achieved [30].

It was elucidated by Park et al. that the chain mobility and volume of the polymeric support membrane (PVDF) increased with raising temperature and as a result higher amount of gas was able to pass through the membrane, leading to enhanced permeability. On the contrary, the work demonstrated that $\mathrm{H}_{2} \mathrm{~S}$ removal was less efficient at elevated temperatures due to the opposite effect of temperature on the diffusion and solubility of penetrating gases in the IL used [77].

From the examples found in the literature one can conclude that an Arrhenius-type relationship represents a satisfactory correlation between temperature and permeability. The effect of temperature on the behavior of SILMs is similar to that it has on conventional, non-porous polymeric membranes and is possibly a consequence of changed physical characteristics of both the support matrix and the ionic liquids (e.g. viscosity, density, etc.) and moreover, it alters the diffusion and solubility properties of specific gases.

\section{Assessing some technical challenges in gas separation membrane bioreactors}

In spite of the limited number of relevant studies, it would appear that integrated systems possess a good opportunity for process enhancement. The combination of the production step (upstream) with membrane separation (downstream) is a well-known, reliable way, however, it needs careful design. For example, as an economical and practical issue, it is important to balance the generation and utilization of $\mathrm{bioH}_{2}$. A possible solution was proposed by Pientka et al. who suggested closed-cell polystyrene foams as pressurized buffers for the temporary storage of separated hydrogen. This application seems useful in cases when biohydrogen demand in fuel cells is not in perfect synch with its production [78].

Furthermore, in the authors' opinion, the following challenges should be considered regarding GSMBR design. However, due to the remarkable lack of experiences with such systems, relevant feedback is needed.

1. Pressure control. As it is known, membrane gas separation requires transmembrane pressure difference for adequate performance. This can be ensured inside or outside the bioreactor. If it is generated within the fermenter then as the pressure increases it will gradually impair the $\mathrm{H}_{2}$ forming activity of the microbes. On the other hand, if we provide the driving force externally by using pumps and compressors, it makes the whole set-up more complex. In addition, the recirculation of $\left(\mathrm{H}_{2}\right.$-lean) gases has to be performed at the pressure existing in the reactor, claiming more precise and tuned process control.

2. Biofilm formation on the membrane. The membranes employed for gas separation are usually made of biocompatible materials. Therefore, in case the fermentation off-gases carry some cells they can be deposited on the surface of the membrane and biofilm formation may be expected as the time passes. This bioactive layer could reduce the efficiency of the membrane and even destroy the membrane's structure. Moreover, the surface biofilm may promote and preserve the undesired e.g. methanogenic organisms, leading to unfavorable operation.

3. Moisture content. As it was detailed above, the presence of water vapor in the gas to be purified could be dis 
advantageous for the separation due to cluster formation inside the membrane hindering the gas transport. Additionally, its condensation on the surface of the membrane can be supportive for biofilm formation and enhance the threat of biofouling.

4. Fermentation control. It is important to properly select the chemicals used for process control. As an example, ammonia is routinely used to adjust and maintain $\mathrm{pH}$ during fermentation. In this case, $\mathrm{NH}_{3}$ concentration could significantly be increased in the gas phase which - similarly to the effect of $\mathrm{H}_{2} \mathrm{~S}$ as mentioned previously - may damage the membrane by disrupting its consistency and thus, cause operational failure (e.g. defects). However, its probability is dependent on the resistance of the membrane material.

\section{Conclusions}

This paper emphasizes the attractiveness of membranes in biohydrogen technology and presents a novel, integrated system concept, the Gas Separation Membrane Bioreactor (GSMBR) for process development. The non-porous, polymeric and supported ionic liquid membranes for the construction of such a specific application are surveyed and the issues concerning membrane operation are demonstrated. As a summary, it can be pointed out that membranes are promising candidates for biohydrogen purification. However, since the experiences with the membranes under real hydrogen fermentation conditions are poor, more research and tests are essential with complex, $\mathrm{H}_{2}$-containing gaseous mixtures in order to reveal which kind of system and operational conditions (e.g. separation temperature and pressure, gas pretreatment to remove or control humidity, etc.) could be the most feasible for the enrichment of $\mathrm{H}_{2}$ - both from technological and economical point of views - in an integrated process, where biohydrogen formation and purification can take place simultaneously. Nevertheless, due to the possible separation limitations of the membranes, i.e. they may not able to ensure the required purity of biohydrogen in a single step, multi-stage or cascade processes - where a membrane is followed by another - may be needed. In addition, several technical difficulties associated with GSMBR systems have been revealed for design considerations.

\section{R E F E R E N C E S}

[1] Abetz V, Brinkmann T, Dijkstra M, Ebert K, Fritsch D, Ohlrogge K. Developments in membrane research: from material via process design to industrial application. Adv Eng Mater 2006;8:328-58.

[2] Ahn J, Chung WJ, Pinnau I, Guiver MD. Polysulfone/silica nanoparticle mixed-matrix membranes for gas separation. J Membr Sci 2008;314:123-33.

[3] Aroon MA, Ismail AF, Matsuura T, Montazer-Rahmati MM. Performance studies of mixed matrix membranes for gas separation: a review. Sep Purif Technol 2010;75:229-42.

[4] Baker RW. Membrane technology and applications. 2nd ed. New York: Wiley; 2000.
[5] Baker RW, Lokhandwala K. Natural gas processing with membranes: an overview. Ind Eng Chem Res 2008;47:2109-21.

[6] Bakonyi P, Nemestóthy N, Ramirez J, Ruiz-Filippi G, BélafiBakó K. E. coli (XL1-BLUE) for continuous fermentation of $\mathrm{bioH}_{2}$ and its separation by polyimide membrane. Int $\mathrm{J}$ Hydrogen Energy 2012;37:5623-30.

[7] Bara JE, Lessmann S, Gabriel CJ, Hatakeyama ES, Noble RD, Gin DL. Synthesis and performance of polymerizable room temperature ionic liquids as gas separation membranes. Ind Eng Chem Res 2007;46:5397-404.

[8] Barrie JA, Platt B. The diffusion and clustering of water vapour in polymers. Polymer 1963;4:303-13.

[9] Basu S, Cano-Odena A, Vankelecom IFJ. Asymmetric Matrimid ${ }^{\circledR} /\left[\mathrm{Cu}_{3}(\mathrm{BTC})_{2}\right]$ mixed-matrix membranes for gas separations. J Membr Sci 2010;362:478-87.

[10] Beggel F, Nowik IJ, Modigell M, Shalygin MG, Teplyakov VV, Zenkevitch VB. A novel gas purification system for biologically produced gases. J Cleaner Prod 2010;18:S43-50.

[11] Bélafi-Bakó K, Búcsú D, Pientka Z, Bálint B, Herbel Z, Kovács KL, et al. Integration of biohydrogen fermentation and gas separation processes to recover and enrich hydrogen. Int J Hydrogen Energy 2006;31:1490-5.

[12] Bernardo P, Drioli E, Golemme G. Membrane gas separation: a review/state of the art. Ind Eng Chem Res 2009;48:4638-63.

[13] Budd PM, Ghanem BS, Makhseed S, McKeown NB, Msayib KJ, Tattershall CE. Polymers of intrinsic microporosity (PIMs): robust, solution processable, organic nanoporous materials. Chem Commun 2004;2:230-1.

[14] Budd PM, Msayib KJ, Tattershall CE, Ghanema ES, Reynolds KJ, McKeown NB, et al. Gas separation membranes from polymers of intrinsic microporosity. J Membr Sci 2005;251:263-9.

[15] Budd PM, McKeown NB, Ghanem BS, Msayib KJ, Fritsch D, Starannikova L, et al. Gas permeation parameters and other physicochemical properties of a polymer of intrinsic microporosity: polybenzodioxane PIM-1. J Membr Sci 2008;325:851-60.

[16] Car A, Stropnik C, Yave W, Peinemann KV. Pebax ${ }^{\circledR /}$ polyethylene glycol blend thin film composite membranes for $\mathrm{CO}_{2}$ separation: performance with mixed gases. Sep Purif Technol 2008;62:110-7.

[17] Carlisle TK, Nicodemus GD, Gina DL, Noble RD. $\mathrm{CO}_{2} /$ light gas separation performance of cross-linked poly(vinylimidazolium) gel membranes as a function of ionic liquid loading and cross-linker content. J Membr Sci 2012;397-398:24-37.

[18] Carstensen F, Apel A, Wessling M. In situ product recovery: submerged membranes vs. external loop membranes. J Membr Sci 2012;394-395:1-36.

[19] Chen GQ, Scholes CA, Qiao GG, Kentish SE. Water vapor permeation in polyimide membranes. J Membr Sci 2011;379:479-87.

[20] Chen H, Xiao Y, Chung TS. Synthesis and characterization of poly(ethylene oxide) containing copolyimides for hydrogen purification. Polymer 2010;51:4077-86.

[21] Choi SH, Jansen JC, Tasselli F, Barbieri G, Drioli E. In-line formation of chemically cross-linked $\mathrm{P} 84^{\circledR}$ co-polyimide hollow fibre membranes for $\mathrm{H}_{2} / \mathrm{CO}_{2}$ separation. Sep Purif Technol 2010;76:132-9.

[22] Chua ML, Shao L, Low BT, Xiao Y, Chung TS. Polyetheramine-polyhedral oligomeric silsesquioxane organic-inorganic hybrid membranes for $\mathrm{CO}_{2} / \mathrm{H}_{2}$ and $\mathrm{CO}_{2} /$ $\mathrm{N}_{2}$ separation. J Membr Sci 2011;385-386:40-8.

[23] Compton J, Thompson D, Kranbuehl D, Ohl S, Gain O, David L. Hybrid films of polyimide containing in situ generated silver or palladium nanoparticles: effect of the 
particle precursor and of the processing conditions on the morphology and the gas permeability. Polymer 2006;47:5303-13.

[24] Couto RM, Carvalho T, Neves LA, Ruivo RM, Vidinha P, Paiva A, et al. Development of Ion-Jelly ${ }^{\circledR}$ membranes. Sep Purif Technol 2013;106:22-31.

[25] Cserjési P, Nemestóthy N, Vass A, Csanádi Zs, BélafiBakó K. Study on gas separation by supported liquid membranes applying novel ionic liquids. Desalination 2009;245:743-7.

[26] Cserjési P, Nemestóthy N, Bélafi-Bakó K. Gas separation properties of supported liquid membranes prepared with unconventional ionic liquids. J Membr Sci 2010;349:6-11.

[27] Das D, Veziroglu TN. Hydrogen production by biological processes: a survey of literature. Int J Hydrogen Energy 2001;26:13-28.

[28] David OC, Gorri D, Urtiaga A, Ortiz I. Mixed gas separation study for hydrogen recovery from $\mathrm{H}_{2} / \mathrm{CO} / \mathrm{N}_{2} / \mathrm{CO}_{2}$ post combustion mixtures using a Matrimid membrane. J Membr Sci 2011;378:359-68.

[29] David OC, Gorri D, Nijmeijer K, Ortiz I, Urtiaga A. Hydrogen separation from multicomponent gas mixtures containing $\mathrm{CO}, \mathrm{N}_{2}$ and $\mathrm{CO}_{2}$ using Matrimid asymmetric hollow fiber membranes. J Membr Sci 2012;419-420:49-56.

[30] Finotello A, Bara JE, Camper D, Noble RD. Roomtemperature ionic liquids: temperature dependence of gas solubility selectivity. Ind Eng Chem Res 2008;47:3453-9.

[31] Friess K, Jansen JC, Bazzarelli F, Izák P, Jarmarová V, Kacrková $\mathrm{M}$, et al. High ionic liquid content polymeric gel membranes: correlation of membrane structure with gas and vapour transport properties. J Membr Sci 2012;415-416:801-9.

[32] Gan Q, Rooney D, Xue M, Thompson G, Zou Y. An experimental study of gas transport and separation properties of ionic liquids supported on nanofiltration membranes. J Membr Sci 2006;280:948-56.

[33] George SC, Thomas S. Transport phenomena through polymeric systems. Prog Polym Sci 2001;26:985-1017.

[34] Hallenbeck PC. Fermentative hydrogen production, principles, progress, and prognosis. Int J Hydrogen Energy 2009;34:7379-89.

[35] Han D, Row KH. Recent applications of ionic liquids in separation technology. Molecules 2010;15:2405-26.

[36] Hao J, Rice PA, Stern SA. Upgrading low-quality natural gas with $\mathrm{H}_{2} \mathrm{~S}$ - and $\mathrm{CO}_{2}$-selective polymer membranes: part II. Process design, economics, and sensitivity study of membrane stages with recycle streams. J Membr Sci 2008;320:108-22.

[37] Harasimowicz M, Orluk P, Zakrewska-Trnadel G, Chmielewski AG. Application of polyimide membranes for biogas purification and enrichment. J Hazard Mater 2007;144:698-702.

[38] Hasbullah H, Kumbharkar S, Ismail AF, Li K. Asymmetric hollow fibre membranes based on ring-substituted polyaniline and investigation towards its gas transport properties. J Membr Sci 2012;397-398:38-50.

[39] Hong SU, Park D, Ko Y, Baek I. Polymer-ionic liquid gels for enhanced gas transport. Chem Commun 2009;46:7227-9.

[40] Horváth R, Orosz T, Bálint B, Wessling M, Koops GH, Kapantaidakis GC, et al. Application of gas separation to recover biohydrogen produced by Thiocapsa roseopersicina. Desalination 2004;163:261-5.

[41] Husken D, Visser T, Wessling M, Gaymans RJ. $\mathrm{CO}_{2}$ permeation properties of poly(ethylene oxide)-based segmented block copolymers. J Membr Sci 2010;346:194-201.

[42] Izák P, Ruth W, Fei Z, Dyson PJ, Kragl U. Selective removal of acetone and butan-1-ol from water with supported ionic liquid-polydimethylsiloxane membrane by pervaporation. Chem Eng J 2008;139:318-21.

[43] Jacquemin J, Husson P, Padua AAH, Majer V. Density and viscosity of several pure and water-saturated ionic liquids. Green Chem 2006;8:172-80.

[44] Jansen JC, Friess K, Clarizia G, Schauer J, Izák P. High ionic liquid content polymeric gel membranes: preparation and performance. Macromolecules 2011;44:39-45.

[45] Kanehashi S, Kishida M, Kidesaki T, Shindo R, Sato S, Miyakoshi $\mathrm{T}$, et al. $\mathrm{CO}_{2}$ separation properties of a glassy aromatic polyimide composite membranes containing high-content 1-butyl-3-methylimidazolium bis(trifluoromethylsulfonyl)imide ionic liquid. J Membr Sci 2013;430:211-22.

[46] Kawakami H, Mikawa M, Nagaoka S. Gas transport properties in thermally cured aromatic polyimide membranes. J Membr Sci 1996;118:223-30.

[47] Khan AL, Cano-Odena A, Gutiérrez B, Minguillón C, Vankelecoma IFJ. Hydrogen separation and purification using polysulfone acrylate-zeolite mixed matrix membranes. J Membr Sci 2010;350:340-6.

[48] Khan AL, Li X, Vankelecom IFJ. SPEEK/Matrimid blend membranes for $\mathrm{CO}_{2}$ separation. J Membr Sci 2011;380:55-62.

[49] Kim DH, Han SK, Kim SH, Shin HS. Effect of gas sparging on continuous fermentative hydrogen production. Int J Hydrogen Energy 2006;31:2158-69.

[50] Kim S, Chen L, Johnson JK, Marand E. Polysulfone and functionalized carbon nanotube mixed matrix membranes for gas separation: theory and experiment. J Membr Sci 2007;294:147-58.

[51] Koros WJ, Chern RT, Stannett V, Hopfenberg HB. Model for permeation of mixed gases and vapors in glassy polymers. J Polym Sci, B Polym Phys 1981;19:1513-30.

[52] Koros WJ, Fleming KG. Membrane-based gas separation. J Membr Sci 1993;83:1-80.

[53] Kraemer JT, Bagley DM. Improving the yield from fermentative hydrogen production. Biotechnol Lett 2007;29:685-95.

[54] Lee KS, Lin PJ, Fangchian K, Chang JS. Continuous hydrogen production by anaerobic mixed microflora using a hollowfiber microfiltration membrane bioreactor. Int J Hydrogen Energy 2007;32:950-7.

[55] Levin DB, Pitt L, Love M. Biohydrogen production: prospects and limitations to practical application. Int J Hydrogen Energy 2004;29:173-85.

[56] Liang TM, Cheng SS, Wu KL. Behavioral study on hydrogen fermentation reactor installed with silicone rubber membrane. Int J Hydrogen Energy 2002;27:1157-65.

[57] Lin H, Freeman BD. Gas solubility, diffusivity and permeability in poly(ethylene oxide). J Membr Sci 2004;239:105-17.

[58] Lin H, Freeman BD. Materials selection guidelines for membranes that remove $\mathrm{CO}_{2}$ from gas mixtures. J Mol Struct 2005;739:57-74.

[59] Lin H, Wagner EV, Freeman BD, Toy LG, Gupta RP. Plasticization enhanced hydrogen purification using polymeric membranes. Science 2006;311:639-42.

[60] Lokhandwala KA, Pinnau I, He Z, Amo KD, DaCosta AR, Wijmans JG, et al. Membrane separation of nitrogen from natural gas: a case study from membrane synthesis to commercial deployment. J Membr Sci 2010;346:270-9.

[61] Lozano LJ, Godinez C, de los Rios AP, HernandezFernandez FJ, Sanchez-Segado S, Alguacil FJ. Recent advances in supported ionic liquid membrane technology. J Membr Sci 2011;376:1-14

[62] Lüdtke O, Behling RD, Ohlrogge K. Concentration polarization in gas permeation. J Membr Sci 1998;146:145-57. 
[63] Maier G, Wolf M, Bleha M, Pientka Z. Gas permeabilities of polymers with indan groups in the main chain. 1: poly(ether ketone)s. J Membr Sci 1998;143:105-13.

[64] Maier G, Wolf M, Bleha M, Pientka Z. Gas permeabilities of polymers with indan groups in the main chain. 2: polyimides. J Membr Sci 1998;143:115-23.

[65] Malika MA, Hashima MA, Nabi F. Ionic liquids in supported liquid membrane technology. Chem Eng J 2011;171:242-54.

[66] Mandal B, Nath K, Das D. Improvement of biohydrogen production under decreased partial pressure of $\mathrm{H}_{2}$ by Enterobacter cloacae. Biotechnol Lett 2006;28:831-5.

[67] McKeown NB, Budd PM. Polymers of intrinsic microporosity (PIMs): organic materials for membrane separations, heterogeneous catalysis and hydrogen storage. Chem Soc Rev 2006;35:675-83.

[68] Modigell M, Schumacher M, Teplyakov VV, Zenkevich VB. A membrane contactor for efficient $\mathrm{CO}_{2}$ removal in biohydrogen production. Desalination 2008;224:186-90.

[69] Mulder MHV. Basic principles of membrane technology. Dordrecht: Kluwer Academic Publishers; 1996.

[70] Nandi R, Sengupta S. Microbial production of hydrogen, an overview. Crit Rev Microbiol 1998;24:61-84.

[71] Nath K, Das D. Improvement of fermentative hydrogen production: various approaches. Appl Microbiol Biotechnol 2004;65:520-9.

[72] Neves LA, Nemestóthy N, Alves VD, Cserjési P, BélafiBakó K, Coelhoso IM. Separation of biohydrogen by supported ionic liquid membranes. Desalination 2009;240:311-5.

[73] Neves LA, Crespo JG, Coelhoso IM. Gas permeation studies in supported ionic liquid membranes. J Membr Sci 2010;357:160-70.

[74] Noble RD, Gin DL. Perspective on ionic liquids and ionic liquid membranes. J Membr Sci 2011;369:1-4.

[75] Park HB, Jung CH, Lee YM, Hill AJ, Pas SJ, Mudie ST, et al. Polymers with cavities tuned for fast selective transport of small molecules and ions. Science 2007;318: 254-8.

[76] Park HB, Han SH, Jung CH, Lee YM, Hill AJ. Thermally rearranged (TR) polymer membranes for $\mathrm{CO}_{2}$ separation. J Membr Sci 2010;359:11-24.

[77] Park YI, Kim BS, Byun YH, Lee SH, Lee EW, Lee JM. Preparation of supported ionic liquid membranes (SILMs) for the removal of acidic gases from crude natural gas. Desalination 2009;236:342-8.

[78] Pientka Z, Pokorny P, Bélafi-Bakó K. Closed-cell polymeric foam for hydrogen separation and storage. J Membr Sci 2007;304:82-7.

[79] Powell CE, Qiao GG. Polymeric $\mathrm{CO}_{2} / \mathrm{N}_{2}$ gas separation membranes for the capture of carbon dioxide from power plant flue gases. J Membr Sci 2006;279:1-49.

[80] Reijerkerk SR, Knoef MH, Nijmeijer K, Wessling M. Poly(ethylene glycol) and poly(dimethyl siloxane): combining their advantages into efficient $\mathrm{CO}_{2}$ gas separation membranes. J Membr Sci 2010;352: 126-35.

[81] Reijerkerk SR, Nijmeijer K, Ribeiro CP, Freeman BD. Wessling. On the effects of plasticization in $\mathrm{CO}_{2} /$ light gas separation using polymeric solubility selective membranes. J Membr Sci 2011;367:33-44.

[82] Robeson LM. The upper bound revisited. J Membr Sci 2008;320:390-400.

[83] Rongwong W, Boributh S, Assabumrungrat S, Laosiripojana N, Jiraratananon R. Simultaneous absorption of $\mathrm{CO}_{2}$ and $\mathrm{H}_{2} \mathrm{~S}$ from biogas by capillary membrane contactor. J Membr Sci 2012;392-393:38-47.
[84] Rowe BW, Robeson LM, Freeman BD, Paul DR. Influence of temperature on the upper bound: theoretical considerations and comparison with experimental results. J Membr Sci 2010;360:58-69.

[85] Scholes CA, Stevens GW, Kentish SE. The effect of hydrogen sulfide, carbon monoxide and water on the performance of a PDMS membrane in carbon dioxide/nitrogen separation. J Membr Sci 2010;350:189-99.

[86] Scovazzo P, Kieft J, Finan DA, Koval C, DuBois D, Noble RD. Gas separations using non-hexafluorophosphate $\left[\mathrm{PF}_{6}\right]^{-}$ anion supported ionic liquid membranes. J Membr Sci 2004;238:57-63.

[87] Scovazzo P, Havard D, McShea M, Mixon S, Morgan D. Longterm, continuous mixed-gas dry fed $\mathrm{CO}_{2} / \mathrm{CH}_{4}$ and $\mathrm{CO}_{2} / \mathrm{N}_{2}$ separation performance and selectivities for room temperature ionic liquid membranes. J Membr Sci 2009;327:41-8.

[88] Scovazzo P. Determination of the upper limits, benchmarks, and critical properties for gas separations using stabilized room temperature ionic liquid membranes (SILMs) for the purpose of guiding future research. J Membr Sci 2009;343:199-211.

[89] Shao L, Low BT, Chung TS, Greenberg AR. Polymeric membranes for the hydrogen economy: contemporary approaches and prospects for the future. J Membr Sci 2009;327:18-31.

[90] Shen L, Bagley DM, Liss SN. Effect of organic loading rate on fermentative hydrogen production from continuous stirred tank and membrane bioreactors. Int J Hydrogen Energy 2009;34:3689-96.

[91] Sholl DS, Johnson JK. Making high-flux membranes with carbon nanotubes. Science 2005;312:1003-4.

[92] Talakesh MM, Sadeghi M, Chenar MP, Khosravi A. Gas separation properties of poly(ethylene glycol)/ poly(tetramethylene glycol) based polyurethane membranes. J Membr Sci 2012;415-416:469-77.

[93] Teplyakov VV, Gassanova LG, Sostina EG, Slepova EV, Modigell M, Netrusov AI. Lab-scale bioreactor integrated with active membrane system for hydrogen production: experience and prospects. Int J Hydrogen Energy 2002;27:1149-55.

[94] Tin PS, Chung TS, Liu Y, Wang R, Liu SL, Pramoda KP. Effects of cross-linking modification on gas separation performance of Matrimid membranes. J Membr Sci 2003;225:77-90.

[95] Uddin MW, Hägg MB. Natural gas sweetening - the effect on $\mathrm{CO}_{2}-\mathrm{CH}_{4}$ separation after exposing a facilitated transport membrane to hydrogen sulfide and higher hydrocarbons. J Membr Sci 2012;423-424:143-9.

[96] Vaughn JT, Koros WJ, Johnson JR, Karvan O. Effect of thermal annealing on a novel polyamide-imide polymer membrane for aggressive acid gas separations. J Membr Sci 2012;401-402:163-74

[97] Visser T, Masetto N, Wessling M. Materials dependence of mixed gas plasticization behavior in asymmetric membranes. J Membr Sci 2007;306:16-28.

[98] Wang H, Paul DR, Chung TS. Surface modification of polyimide membranes by diethylenetriamine (DETA) vapor for $\mathrm{H}_{2}$ purification and moisture effect on gas permeation. J Membr Sci 2013;430:223-33.

[99] Xiao Y, Low BT, Hosseini SS, Chung TS, Paul DR. The strategies of molecular architecture and modification of polyimide-based membranes for $\mathrm{CO}_{2}$ removal from natural gas - a review. Prog Polym Sci 2009;34:561-80.

[100] Yampolskii Y. Polymeric gas separation membranes. Macromolecules 2012;45:3298-311.

[101] Yave W, Car A, Peinemann KV, Shaikh MQ, Rätzke K, Faupel F. Gas permeability and free volume in poly(amide- 
b-ethylene oxide)/polyethylene glycol blend membranes. J Membr Sci 2009;339:177-83.

[102] Yoon IN, Yoo S, Park SJ, Won J. $\mathrm{CO}_{2}$ separation membranes using ion gels by self-assembly of a triblock copolymer in ionic liquids. Chem Eng J 2011;172:237-42.

[103] Yun S, Oyama ST. Correlations in palladium membranes for hydrogen separation: a review. J Membr Sci 2011;375:28-45.
[104] Zhao W, He G, Zhang L, Ju J, Dou H, Nie F, et al. Effect of water in ionic liquid on the separation performance of supported ionic liquid membrane for $\mathrm{CO}_{2} / \mathrm{N}_{2}$. J Membr Sci 2010;350:279-85.

[105] Zhao W, He G, Nie F, Zhang L, Feng H, Liu H. Membrane liquid loss mechanism of supported ionic liquid membrane for gas separation. J Membr Sci 2012;411-412:73-80.

Please cite this article in press as: Bakonyi $\mathrm{P}$, et al., Biohydrogen purification by membranes: An overview on the operational conditions affecting the performance of non-porous, polymeric and ionic liquid based gas separation membranes, International Journal of Hydrogen Energy (2013), http://dx.doi.org/10.1016/j.ijhydene.2013.05.158 